\title{
STUDY OF FOETOMATERNAL OUTCOME IN CASES OF PLACENTA PREVIA
}

\author{
Jigar K. Thakkar1, Sukun J. Thakkar ${ }^{2}$ \\ ${ }_{1}^{1}$ Senior Resident, Department of Obstetrics and Gynaecology, LG Hospital, Ahmedabad, Gujarat. \\ 2Senior Resident, Department of Obstetrics and Gynaecology, GCS Hospital, Ahmedabad, Gujarat.
}

\section{BACKGROUND}

\section{ABSTRACT}

Placenta previa refers to the location of placenta that overlies or is proximate to the internal os of the cervix. It is a major cause of third trimester bleeding. It is a major cause of obstetric and perinatal morbidity and mortality.

\section{MATERIALS AND METHODS}

Present study is a Descriptive Study of 107 cases of placenta previa, which were admitted at our institute during the time from $1^{\text {st }}$ July 2015 to $30^{\text {th }}$ June 2017.

\section{RESULTS}

Incidence of placenta previa in this study is $107 / 17,472(0.61 \%)$. In the present study, almost $92 \%$ of cases are below the age of 35 years. Data analysis shows multiparity (85\%), previous caesarean section (47.7\%) and history of abortion followed by D and E $(14.9 \%)$ as aetiological factors for placenta previa. $94.4 \%$ of patients were delivered by caesarean section. Total perinatal mortality was 15/107 (8 IUD and 7 expired). 7 patients required obstetric hysterectomy.

\section{CONCLUSION}

In the present study advancing maternal age, multiparity, prior caesarean section and prior abortions were found to have significant association with placenta previa. With early availability of blood transfusion, better surgical facility, anaesthetist and liberal use of caesarean section have reduced maternal morbidity and mortality.

\section{KEY WORDS}

Placenta Previa, Caesarean Section, Obstetric Hysterectomy.

HOW TO CITE THIS ARTICLE: Thakkar JK, Thakkar SJ. Study of foetomaternal outcome in cases of placenta previa. J. Evolution Med. Dent. Sci. 2018;7(19):2329-2332, DOI: $10.14260 /$ jemds/2018/525

\section{BACKGROUND}

Placenta previa refers to the location of placenta that overlies or is proximate to the internal os of the cervix. ${ }^{1}$ The Latin word previa means going before and in this sense the placenta goes before the foetus into the birth canal.

It is the major cause of third trimester bleeding. ${ }^{2}$ It is the major cause of obstetric and perinatal morbidity and mortality. ${ }^{3}$

As the placental growth slows down in later month of pregnancy and the lower segment progressively dilates, the inelastic placenta is sheared off the wall of the lower segment. This leads to opening up of uteroplacental vessels and leads to an episode of bleeding. As it is a physiological phenomenon which leads to the separation of the placenta, the bleeding is said to be inevitable. Separation of the placenta may be provoked by trauma including vaginal examination, coital act, external version or during high rupture of the membranes.

Incidence of placenta previa is estimated to be 4 to 5 per 1000 pregnancies. Incidence has increased due to increased number of prior caesarean sections. Maternal morbidity and mortality occur due to haemorrhage, increased operative interference and

'Financial or Other Competing Interest': None.

Submission 25-03-2018, Peer Review 23-04-2018,

Acceptance 30-04-2018, Published 07-05-2018.

Corresponding Author:

Jigar K. Thakkar,

D/502, Takshshila Resicom,

Near Idli Char Rasta, Maninagar (e),

Ahmedabad, Gujarat.

E-mail: jigarthakkar19@gmail.com

DOI: $10.14260 /$ jemds $/ 2018 / 525$

\section{(c) $($ ) $\$$}

need of blood transfusion, and adherent placenta. Perinatal morbidity and mortality occur due to prematurity, respiratory distress syndrome and low birth weight.

There are Four Types of Placenta Previa depending upon the Degree of Extension of Placenta to the Lower Segment ${ }^{4}$

Type 1- Low Lying Placenta

The major part of the placenta is attached to the upper segment and only the lower margin encroaches onto the lower segment.

\section{Type 2- Marginal Placenta Previa}

The placenta reaches the margin of the internal os, but does not cover it.

\section{Type 3- Incomplete or Partial Placenta Previa}

The placenta partially covers the os, but does not cover it completely after full cervical dilatation.

\section{Type 4- Complete or Central Placenta Previa}

The placenta is almost centrally placed over internal os and likely to cover it even at full dilatation.

Each of the first three type is subdivided into type A and $\mathrm{B}$, depending on whether the placenta mainly lies on the anterior or posterior wall respectively. Posterior is slightly more common and more dangerous, because it discourages engagement of the head more often and the placenta is likely to be compressed in labour impairing placental perfusion.

For clinical purpose, the types are graded into MILD degree (Type- 1 and 2 anterior) and MAJOR degree (Type- 2 posterior, 3 and 4). 
Placenta accreta refers to a placenta that is abnormally adherent to the uterus. When the placenta invades the myometrium, the term Placenta increta is used, whereas Placenta percreta refers to placenta that has invaded through the myometrium and serosa, sometimes into adjacent organs such as the bladder.

Accreta is the most common form of abnormally adherent placenta accounting for $80 \%$, increta for $15 \%$ and $5 \%$ are percreta.

Ultrasonography can help in diagnosis of location of placenta and Doppler can diagnose invasion of placenta into uterus. ${ }^{5}$ Early diagnosis allows patient identification and institution of appropriate treatment measures to minimise complications. ${ }^{3}$

Mainstay of management in case of placenta previa is early diagnosis, careful evaluation with timely intervention by appropriate mode of delivery by team of obstetricians, trained nursing staff, anaesthetists. A well-equipped laboratory, blood bank facility and neonatal care units are backbone of proper treatment of placenta previa. Due to all these facilities, maternal and foetal outcome have significantly improved in present day obstetrics.

There has been marked improvements in transportation and communication facilities. Even patients from remote areas can be transferred to tertiary care centres and managed efficiently.

The current study was done to study and determine the risk factors and to find out maternal and foetal outcome in the patients of placenta previa in our institute during the period from July 2015 to June 2017.

\section{MATERIALS AND METHODS}

The present study is a descriptive study of 107 cases of placenta previa, which were admitted at our institute during the time from $1^{\text {st }}$ July 2015 to $30^{\text {th }}$ June 2017 -

- Patient from any age is included in this study.

- Both emergency and registered cases are included. Some patients which are referred from other hospitals are also included.

- Some patients came with the complaint of vaginal bleeding. While some are diagnosed antenatally during routine sonography examinations. All cases are followed till termination of pregnancy.

- Some patients went into labour spontaneously, while others are electively terminated due to heavy bleeding or foetal heart abnormalities.

\section{RESULTS}

This is a prospective study of 107 cases of placenta previa admitted during July 2015 to June 2017 at our hospital. Out of 17,472 deliveries during this period, 107 patients were detected with placenta previa. Incidence of placenta previa in this study was $107 / 17,472(0.61 \%)$.

\begin{tabular}{|c|c|c|}
\hline Age Group (in Years) & No. of Cases & Percentage \\
\hline$<20$ years & 3 & $2.8 \%$ \\
\hline $20-24$ years & 20 & $18.7 \%$ \\
\hline $25-29$ years & 47 & $43.9 \%$ \\
\hline $30-34$ years & 28 & $26.2 \%$ \\
\hline$>35$ years & 9 & $8.4 \%$ \\
\hline \multicolumn{2}{|c|}{ Table 1. Age Groups and No. of Cases } \\
\hline
\end{tabular}

Maximum number of cases belonged to age group of 25 29 years $(47 / 107$ cases $)$ followed by $30-34$ years $(28 / 107$ cases). In the present study, almost $92 \%$ of cases are below age of 35 years. Earlier age of marriage in our country and at short interval of pregnancy are main reasons for having high numbers of patients below 35 years.

\begin{tabular}{|c|c|c|}
\hline Parity & Primipara & Multipara \\
\hline No. of cases & 16 & 91 \\
\hline Percentage & $15 \%$ & $85 \%$ \\
\hline \multicolumn{2}{|c|}{ Table 2. Parity and Risk of Placenta Previa } \\
\hline
\end{tabular}

Multiparous patients (85\%) have higher incidence of placenta previa than primipara. Thus, it shows that placenta previa is more common in multiparous patients.

\begin{tabular}{|c|c|c|}
\hline Risk Factors & No. of Cases & Percentage \\
\hline Multiparity & 91 & $85 \%$ \\
\hline Previous CS & 51 & $47.7 \%$ \\
\hline Abortion F/B D and E & 16 & $14.9 \%$ \\
\hline \multicolumn{2}{|r|}{ Table 3. Aetiological Factor } \\
\hline
\end{tabular}

In the present study data analysis shows multiparity (85\%), previous caesarean section (47.7\%) and history of abortion followed by D and E (14.9\%) as aetiological factors for placenta previa.

\begin{tabular}{|c|c|c|c|c|}
\hline Mode of & Total & \multicolumn{2}{|c|}{ Foetal Outcome } & NICU \\
\cline { 3 - 4 } Delivery & Deliveries & LB & IUD & Admission \\
\hline Caesarean & 101 & 96 & 5 & 25 \\
\hline Vaginal & 6 & 3 & 3 & 3 \\
\hline Total & $\mathbf{1 0 7}$ & $\mathbf{9 9}$ & $\mathbf{8}$ & $\mathbf{2 8}$ \\
\hline
\end{tabular}

- $\quad 94.4 \%$ of patients were delivered by caesarean section.

- $\quad$ Out of caesarean delivered patients (101), 96 were live born and 5 were IUD.

- 25 babies delivered by caesarean section were admitted to NICU.

- Only $6(5.6 \%)$ patients with low lying placenta were delivered vaginally. Among them, 3 were IUD and remaining 3 babies were admitted to NICU.

\begin{tabular}{|c|c|c|c|}
\hline No. & $\begin{array}{c}\text { Neonatal } \\
\text { Complication }\end{array}$ & $\begin{array}{c}\text { No. of NICU } \\
\text { Admission }\end{array}$ & Outcome \\
\hline 1 & RDS & 3 & $\begin{array}{c}\text { Discharged well, } \\
\text { 1 expired }\end{array}$ \\
\hline 2 & Jaundice & 3 & Discharged well \\
\hline 3 & Septicaemia & 2 & $\begin{array}{c}\text { Discharged well, } \\
\text { 1 Expired }\end{array}$ \\
\hline 4 & MSL & 1 & 1 Expired \\
\hline 5 & LBW & 19 & $\begin{array}{c}\text { 15 Discharged } \\
\text { well, } \\
\text { 4 Expired }\end{array}$ \\
\hline Total & & 28 & $\begin{array}{c}\text { 21 Discharged } \\
\text { well, } \\
\text { 7 Expired }\end{array}$ \\
\hline \multicolumn{2}{|r|}{ Table 5. Neonatal Complications and Mortality } \\
\hline
\end{tabular}

Total perinatal mortality was $15 / 107$ (8 IUD and 7 expired). 4 babies expired due to low birth weight due to prematurity, 1 due to respiratory distress syndrome, 1 due to septicaemia and 1 due to MSL.

Because of highly equipped NICU and good ventilator care, babies were promptly treated which decreased morbidity in babies. 


\begin{tabular}{|c|c|c|c|}
\hline No. & $\begin{array}{c}\text { Maternal } \\
\text { Complications }\end{array}$ & $\begin{array}{c}\text { No. of } \\
\text { Patients }\end{array}$ & Percentage \\
\hline 1 & Postpartum haemorrhage & 12 & $11.2 \%$ \\
\hline 2 & Hypovolaemic shock & 4 & $3.7 \%$ \\
\hline 3 & Obstetric hysterectomy & 7 & $6.5 \%$ \\
\hline 4 & Fever & 2 & $1.9 \%$ \\
\hline 5 & Wound infection & 3 & $2.8 \%$ \\
\hline 6 & Maternal mortality & 0 & 0 \\
\hline \multicolumn{3}{|c|}{ Table 6. Maternal Complications } \\
\hline
\end{tabular}

Chances of postpartum haemorrhage is more in cases of placenta previa due to imperfect retraction of the lower uterine segment, where the placenta was implanted. In this study, 12 patients developed postpartum haemorrhage which were managed as below:

\begin{tabular}{|c|c|c|}
\hline No. & Mode of Treatment & No. of Cases \\
\hline 1 & Medical management & 4 \\
\hline 2 & $\begin{array}{c}\text { Figure-of-eight sutures over placental } \\
\text { implantation site }\end{array}$ & 6 \\
\hline 3 & B/L uterine artery ligation & 7 \\
\hline 4 & Intrauterine packing & 2 \\
\hline 5 & B/L internal iliac artery ligation & 1 \\
\hline 6 & Obstetric hysterectomy & 7 \\
\hline \multicolumn{3}{|c|}{ Table 7. Mode of Treatment in PPH } \\
\hline
\end{tabular}

For management of PPH, different modalities of treatment were used with simultaneous use of one or more mode of treatments required.

Four patients were managed conservatively with medical management.

One patient was treated with figure-of-eight sutures over placental implantation site.

One patient was treated with figure-of-eight sutures along with bilateral uterine artery ligation.

Bilateral uterine artery ligation and intrauterine packing was done in two patients.

In one patient, internal iliac artery ligation was done along with figure-of-eight sutures over placental implantation site and bilateral uterine artery ligation for $\mathrm{PPH}$.

7 patients had undergone obstetric hysterectomy, out of which 4 patients had placenta accreta and 3 for PPH when other modalities of treatment (Figure-of-eight sutures over placental implantation site and bilateral uterine artery ligation) failed.

\begin{tabular}{|c|c|c|}
\hline Group & No. of Cases & Percentage \\
\hline Registered cases & 49 & $45.8 \%$ \\
\hline Emergency cases & 58 & $54.2 \%$ \\
\hline
\end{tabular}

Table 8. Type of Admission (Registered/ Emergency Case)

In present study 49/107 (45.8\%) were registered patients and 58/107 (54.2\%) were emergency cases.

Out of emergency cases, 40/58 (69\%) were prediagnosed placenta previa referred from other centres due to unavailability of blood transfusion or facility of neonatal care unit.

Due to early diagnosis by ultrasonography and follow-up by patients, disparities between emergency and registered patients has reduced.

\section{DISCUSSION}

Maximum number of patients were among 25 - 29 years of age group (Table 1), which is comparable to Akkamamba $\mathrm{B}^{6}$ study.

Multiparity (85\%), history of previous caesarean section $(47.7 \%)$ and abortions followed by dilatation and evacuation $(14.9 \%)$ were among the major aetiological factors found in the present study of placenta previa (Table 2, 3), which is similar to Rajeshwari RR et al, ${ }^{7}$ Shinde V et al, ${ }^{8}$ Ojha $\mathrm{N}^{9}$ and Kaur B et $\mathrm{al}^{10}$ studies.

Incidence of caesarean section was high in the present study (94.4\%) (Table 4). Out of caesarean section delivered babies, 5 were IUD and 25 were admitted in NICU. And out of vaginal delivered babies, 3 were IUD and 3 were admitted in NICU (Table 5). In the present study $94.4 \%$ of patients were delivered by caesarean section, which is quite high, but that has decreased perinatal morbidity and mortality which satisfies the aim of the present study. It is comparable to Rangaswamy $\mathrm{M}$ et al ${ }^{11}$ study.

$11.2 \%$ of cases suffered from postpartum haemorrhage (Table 6), which is quite common in placenta previa. ${ }^{12} 6.5 \%$ cases underwent obstetric hysterectomy (Table 7), which is comparable to Rangaswamy $\mathrm{M}$ et al $^{11}$ study and Maiti S et $\mathrm{al}^{13}$ study.

Maternal mortality in the present study is zero. Decrease in maternal mortality is due to early and accurate diagnosis of placenta previa by Ultrasound and Doppler and increased availability of medical care and blood transfusion facilities.

49/107 (45.8\%) were registered patients and 58/107 $(54.2 \%)$ were emergency cases in the present study (Table 8). It is compared to Akkamamba $\mathrm{B}^{6}$ study, in which $40 \%$ were registered patients and $60 \%$ were emergency patients.

\section{CONCLUSION}

- Placenta previa presenting as APH in third trimester is one of the gravest obstetric emergencies. Even with the best obstetric care due to dramatic suddenness, a pregnant woman can become exsanguinated due to severe bleeding. Neonates born to them are at a higher risk of premature birth, low APGAR score and increased admission to NICU.

- In the present study advancing maternal age, multiparity, prior caesarean section and prior abortions were found to have significant association with placenta previa. An increase in the incidence of these risk factors probably contributes to a rise in the number of pregnancies complicated with placenta previa.

- The present study concludes that efforts should be made to reduce the rates of operative deliveries, because there is greater likelihood of placenta previa in scarred uterus in subsequent pregnancies.

- Women who had placenta previa in their previous pregnancy were at increased risk of placenta previa in current pregnancy. Clinicians should consider this factor when counselling their patients.

- Sonographic diagnosis of low lying placenta is very important to detect asymptomatic cases, which may cause major management challenges when presented as an emergency.

- The detection of placenta previa should encourage a careful evaluation with timely delivery in order to 


\section{Jemds.com}

reduce the associated maternal and perinatal complications.

- The family planning services should be further improved to attain a decline in the number of women with high parity.

- Educating our patients and making them aware of the importance of antenatal care and its availability is very important.

- Managing a case of placenta previa during pregnancy poses a great challenge to every obstetrician in present day obstetrics due to high maternal morbidity and mortality. With early availability of blood transfusion, better surgical facility, anaesthetist and liberal use of caesarean section have improved maternal morbidity and mortality.

\section{REFERENCES}

[1] Oyelese Y, Smulian JC. Placenta previa, Placenta accrete and vasa previa. Obstet Gynecol 2006;107(4):927-41.

[2] Faiz AS, Ananth CV. An overview and meta-analysis of placenta previa. Abstr Acad Health Serv Res Health Policy Meet 2002;19:4.

[3] Loto 0, Onile TG. Placenta praevia at the Obafemi Awolowo University Teaching Hospital Complex, IleIfe. A ten year analysis. Niger J Clin Pract 2008;11(2):130-3.

[4] Cunningham G, Kenneth J. Obstetrical hemorrhage. Williams's obstetrics. 24th edn. McGrawHill Education 2014: p. 780-828.

\section{Original Research Article}

[5] Gottesfeld KR, Thompson JH, Holmes JH, et al. Ultrasound placentography: a new method for placental localization. Am J Obstet Gynecol 1966;96(4):538-47.

[6] Akkamamba B, Padmanalini P, Kumari GR. Maternal and foetal outcome in placenta previa. J Evid Based Med Healthc 2016;3(93):5081-5.

[7] Rajeshwari RR, Rubini M. Maternal and perinatal outcome in placenta previa. Int J Reprod Contracept Obstet Gynecol 2016;5(8):2819-22.

[8] Shinde V, Lakshmim R. A study on maternal and neonatal outcomes in placenta previa in a tertiary level hospital in India. International Journal of Medical Science and Clinical Inventions 2015;2(12):1480-4.

[9] Ojha N. Obstetric factors and pregnancy outcome in placenta previa. Journal of Institute of Medicine 2012;34(2):38-41.

[10] Kaur B. Incidence, risk factors and neonatal outcomes in placenta previa. International Journal of Basic and Applied Medical Sciences 2015;5(3):58-61.

[11] Rangaswamy M, Govindaraju K. Fetomaternal outcome in placenta previa. Int J Reprod Contracept Obstet Gynecol 2016;5(9):3081-4.

[12] El-Hamamy E, B-Lynch C. A worldwide review of the uses of the uterine compression suture techniques as alternative to hysterectomy in the management of severe post-partum haemorrhage. Journal of Obstetrics and Gynaecology 2005;25(2):143-9.

[13] Maiti S, Kanrar P, Karmakar C, et al. Maternal and perinatal outcome in rural Indian women with placenta previa. British Biomedical Bulletin 2014;2(4):714-8. 